\title{
Synthetic Lethal Screens as a Means to Understand and Treat MYC-Driven Cancers
}

\author{
Silvia Cermelli ${ }^{1}$, In Sock Jang ${ }^{2}$, Brady Bernard ${ }^{3}$, and Carla Grandori ${ }^{1}$ \\ ${ }^{1}$ Human Biology Division, Fred Hutchinson Cancer Research Center, Seattle, Washington 98109 \\ ${ }^{2}$ SAGE Bionetworks, Seattle, Washington 98109 \\ ${ }^{3}$ Institute for Systems Biology, Seattle, Washington 98109 \\ Correspondence: cgrandor@fhcrc.org
}

\begin{abstract}
Although therapeutics against MYC could potentially be used against a wide range of human cancers, MYC-targeted therapies have proven difficult to develop. The convergence of breakthroughs in human genomics and in gene silencing using RNA interference (RNAi) have recently allowed functional interrogation of the genome and systematic identification of synthetic lethal interactions with hyperactive MYC. Here, we focus on the pathways that have emerged through RNAi screens and present evidence that a subset of genes showing synthetic lethality with MYC are significantly interconnected and linked to chromatin and transcriptional processes, as well as to DNA repair and cell cycle checkpoints. Other synthetic lethal interactions with MYC point to novel pathways and potentially broaden the repertoire of targeted therapies. The elucidation of MYC synthetic lethal interactions is still in its infancy, and how these interactions may be influenced by tissue-specific programs and by concurrent genetic change will require further investigation. Nevertheless, we predict that these studies may lead the way to novel therapeutic approaches and new insights into the role of MYC in cancer.
\end{abstract}

U sing a synthetic lethal RNA interference approach, several groups have recently identified genes whose function is selectively required for the survival of MYC-overexpressing cells (Kessler et al. 2012; Liu et al. 2012; Toyoshima et al. 2012). Analysis of these genes, referred to as MYC-synthetic lethal (MYC-SL) genes, provides new insights into cellular pathways that contribute to the fitness of cells with aberrant MYC expression. Moreover MYC-SL genes provide a menu of possible therapeutic targets, potentially circumventing the difficulties inherent in targeting MYC itself. Inhibition of $M Y C-S L$ genes has the potential to halt cancers driven by aberrant MYC expression, while sparing normal tissues. In fact, by selecting for genetic interactions that occur only in the context of MYC overexpression, the proliferation of normal cells, where MYC function is tightly regulated, may not be affected. Here, we highlight MYC synthetic lethal genes and networks that have emerged from RNA interference screens, and we describe their relationship to known and novel functions of MYC. Finally, we discuss therapeutic implications and challenges surrounding the exploitation of synthetic lethal

Editors: Chi V. Dang and Robert N. Eisenman

Additional Perspectives on MYC and the Pathway to Cancer available at www.perspectivesinmedicine.org

Copyright (C) 2014 Cold Spring Harbor Laboratory Press; all rights reserved; doi: 10.1101/cshperspect.a014209

Cite this article as Cold Spring Harb Perspect Med 2014;4:a014209 
S. Cermelli et al.

interactions in clinical settings of MYC-driven cancers.

\section{LEARNING FROM YEAST GENETIC NETWORKS}

In Saccharomyces cerevisiae (S. cerevisiae) and other single-cell organisms, systematic genome-wide mapping of both positive and negative genetic interactions that affect cell viability have been performed (for review, see Dixon et al. 2009; Costanzo et al. 2012). Positive interactions describe double mutants whose fitness is increased relative to the effect of each individual mutation, and are often defined as suppressing or rescuing mutations. Of relevance to the topic of synthetic lethality are negative digenic interactions, wherein the combination of mutations in two different genes leads to a significant loss of fitness from the expected additive effects of the individual phenotypes. Synthetic lethality defines an extreme form of negative genetic interaction, as, for example, when mutations in two otherwise nonessential genes lead to cell death. The graphical representation in Figure 1A illustrates the concept of synthetic lethality applied to MYC-overexpressing cells. In this instance, the first aberration is the presence of MYC overexpression, achieved by either a retroviral vector or through expression of a conditional MYC-ER fusion. When loss of function of a second gene is achieved, the consequences
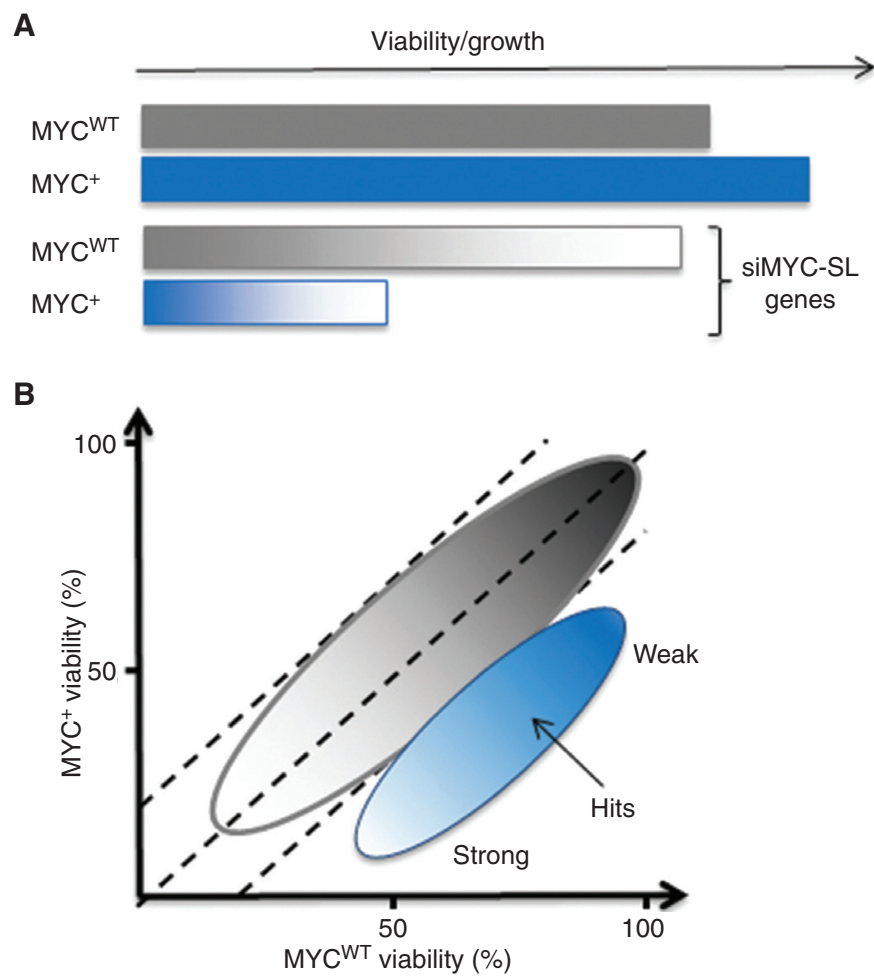

Figure 1. Graphical representation of synthetic lethal interactions applied to MYC overexpression. (A) Growth/ viability of normal cells expressing endogenously controlled levels of MYC ${ }^{\mathrm{WT}}$ (gray) in comparison with cells overexpressing MYC (blue, $\mathrm{MYC}^{+}$). A gene is here defined as "synthetic lethal" with MYC overexpression if its knockdown minimally impacts viability/growth in the control cells, MYC ${ }^{\mathrm{WT}}$, while leading to loss of viability in $\mathrm{MYC}^{+}$cells. (B) Schematic of results obtained from arrayed siRNA screening. Although most of the siRNAs similarly affect $\mathrm{MYC}^{\mathrm{WT}}$ and $\mathrm{MYC}^{+}$cells, with a gradient illustrating the lower abundance of highly toxic siRNAs, a small subset confers selective growth inhibition in $\mathrm{MYC}^{+}$(blue oval). "Strong" hits lead to a dramatic loss of viability (below $\sim 20 \%$ ) in contrast to "weak" hits, also referred to as "synthetic sick" (see text for details). 
for cell viability in normal cells versus MYCoverexpressing cells enable the identification of genes showing a "synthetic lethal" or "synthetic sick" interaction (Fig. 1B). From these studies, both potential candidate therapeutic targets as well as insights into MYC-induced vulnerabilities and functionally linked pathways have emerged.

In yeast, positive interactions are frequently observed among genes whose products physically interact, whereas negative interactions generally occur between genes working within parallel biological pathways. In fact, many genes affecting DNA repair processes show synthetic lethal interactions, perhaps reflecting the evolution of robust buffering systems that ensure DNA stability. The example of synthetic lethal interaction between BRCA mutants and PARP fits this model because both genes act in parallel to repair DNA breaks through homologous recombination. Accordingly, PARP inhibitors have exquisite efficacy toward cancers that carry homozygous loss-of-function mutations in the $B R C A$ gene (McCabe et al. 2005; Fong et al. 2009). The high therapeutic window of PARP inhibitors is likely due to the minimal toxicity to noncancerous tissues harboring one or two functional copies of the BRCA gene, thus retaining some capacity to repair DNA breaks under PARP inhibition. The example of BRCA and PARP interaction is consistent with the relatively high frequency of synthetic lethality among functionally related genes $(18 \%-25 \%)$, in contrast to its rarity among unrelated genes $(<1 \%)$ (Dixon et al. 2009). In fact, unbiased genetic mapping has enabled the assignment of novel functions to genes included in networks based on genetic interactions as shown in yeast (Dixon et al. 2009) and illustrated here for MYC. These novel interactions point to unexpected drug targets and shed new light on MYC-mediated tumorigenesis.

The potential to exploit synthetic lethality between cancer-causing mutations and nonessential cellular pathways as a means to identify novel drug targets was proposed in 1997 in a landmark paper (Hartwell et al. 1997). However, broadly identifying synthetic lethal interactions was then not possible in mammalian cells, because the methodology had yet to be developed for efficient gene targeting and functional interrogation in cell culture. Thus, synthetic lethality in mammalian cells had only been observed via a candidate hypothesis-driven process, verified by time-consuming intercrosses of knockout mouse mutant strains (Gurley and Kemp 2001) or availability of mutant cells. Only recently has a systematic testing of genegene interactions, or "functional genomics," become feasible in mammalian cells as a consequence of the convergence of three major breakthroughs: (1) knowledge of the human genome; (2) the discovery of RNA interference, which enabled the targeting of virtually all proteincoding genes; and (3) the availability of robotics equipment to achieve truly massive parallel testing, in a single query, of thousands of gene knockdowns, as shown in Figure 1A and B. The availability of unbiased, high-throughput empirical testing enables the construction of large-scale functional networks centered on known oncogenes.

\section{OVERVIEW OF RNA INTERFERENCE SCREENS}

Synthetic lethal screens in mammalian cells ideally use isogenic systems where the only difference between two cell types is the mutation of a single gene, such as amplification of an oncogene or mutation of a tumor suppressor. In the case of MYC, screens have used MYC overexpression, which reflects the alteration observed in many cancers (Nesbit et al. 1999). The screen by Toyoshima et al. (2012) used primary human-foreskin fibroblasts (HFFs) where MYC was constitutively expressed through a retroviral vector. HFFs provide a unique cell background where oncogene activation does not induce senescence (Benanti and Galloway 2004; Benanti et al. 2007). The level of MYC expression mimicked the deregulation observed in cancer cells and caused MYC-related phenotypes and gene expression signatures (Grandori et al. 2005; Dominguez-Sola et al. 2007; Wang et al. 2011). A different approach was taken in separate screens by Kessler et al. (2012) and Liu et al. (2012), who used mammary epithelial cells and 


\section{S. Cermelli et al.}

the U2OS osteosarcoma cell line to express a MYC-estrogen receptor fusion protein (Eilers et al. 1989), respectively. MYC was conditionally activated by the addition of tamoxifen.

Kessler's study used a pooled approach, in which short hairpin RNAs (shRNAs) are expressed from lentiviral vectors, whereas Toyoshima and Liu used a one-gene-per-well meth- od, also referred to as an arrayed approach. A schematic of the steps involved in these two types of screens is shown in Figure 2. The pooled approach, in principle, enables the interrogation of the entire human transcriptome at once (about 30,000 different genes), by transducing a cell population with large-scale shRNA-expressing lentiviral libraries (Fig. 2A) (Paddison

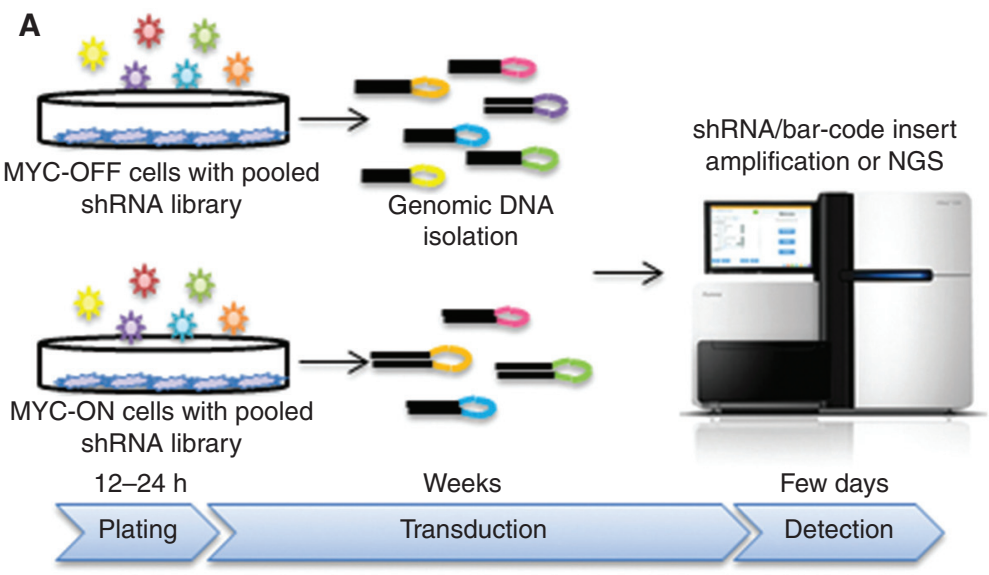

B

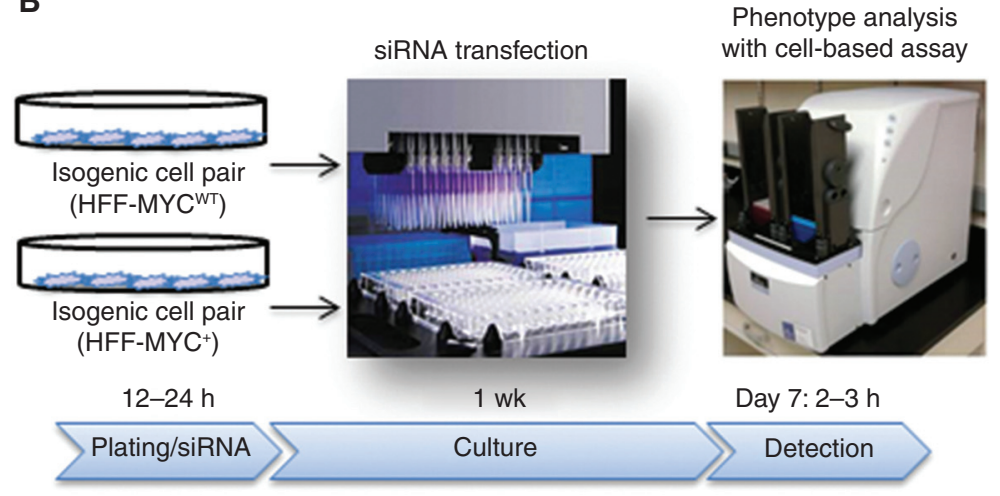

Figure 2. Workflow of RNAi screening approaches to identify synthetic lethal interactions with MYC activation. (A) shRNA pooled approach (Kessler et al. 2012). Breast epithelial cells, HMECs, expressing the conditional MYC-ER fusion were transduced with a genome-wide shRNA lentiviral library in three independent replicates. Following transduction, cells were cultured for 12 population doublings in the presence or absence of tamoxifen to induce MYC-ER activity. To identify hits, genomic DNA was isolated, and the relative change in shRNAbarcode was measured in both states (MYC-ON and MYC-OFF). Approximately 400 genes with more then twofold under-representation were identified as candidate MYC-SL genes. (B) siRNA arrayed approach (Toyoshima et al. 2012). Isogenic HFFs with or without exogenous MYC overexpressed from a retroviral vector were transfected with siRNAs (3/gene) toward a custom collection of about 3000 druggable genes. The screen was performed in triplicate with 384-well plates. Following a 5-d incubation period, cell viability was measured using an automated plate reader; about 100 genes emerged from this screen. Liu et al. (2012) also used the arrayed approach in an osteosarcoma line (see text for details) (Liu et al. 2012). 
et al. 2004; Hu et al. 2009; Blakely et al. 2011). This approach permits measuring the effect of selective loss of individual shRNAs on growth of the cell population and is referred to as a dropout screen. The use of stable lentiviral transductions allows for long-term gene knockdown in a variety of cell types and can be performed in most laboratory settings. Genome-wide dropout screens suffer from lower sensitivity due to the difficulties in identifying negatively selected shRNA in complex libraries. Focused libraries may be a valuable alternative (Zuber et al. 2011) .

Toyoshima's screen used an arrayed siRNA approach, which takes advantage of liquid handling robotics and automated readout instruments (Chung et al. 2008), allowing the rapid interrogation of an approximately 3000-druggable-genomes library by testing independently the effect of individual gene knockdowns (Fig. 2B) (for details of the method, see Grandori 2013). By performing the screen in triplicate and through the use of optimal siRNA design, an increased confidence in the "hits" could be achieved as shown by an $\sim 98 \%$ confirmation through independent retesting of the "hits." Also, as shown in the schematic in Figure 1B, because the arrayed approach directly quantifies the degree of cell toxicity induced by each gene knockdown, it also allows for the detection of weaker or "synthetic sick" hits (Fig. 1B).

When evaluating MYC-SL genes, it is important to keep in mind the limitations of RNA interference, mainly due to incomplete and transitory gene inhibition. Therefore, screens may underestimate the consequences of longterm and more complete gene inhibition. For example, we have found that "weak" hits from siRNA screens when more stably silenced can lead to abrogation of colony formation or block tumor growth (Toyoshima et al. 2012; C Grandori, unpubl.). Similarly, "strong" hits tend to show higher toxicity in normal cells when stably inhibited. In summary, RNA interference screens represent a first filter to identify synthetic lethal interactions, and prioritization of genes should not be based solely on statistical considerations, but strengthened by genomic analysis and multiplexed validation in the context of cancer and normal cells. In the near future, the identification of MYC-SL interactions could be broadened to different cancer types and mechanistic assays focused on chromatin, apoptosis, stemness, or metabolic aspects. The types of assays are nearly limitless when the use of automated microscopy and other high-throughput devices is considered. One example was provided by the kinome-focused screen that used a PARP-cleavage assay to monitor apoptosis through automated microscopy (Liu et al. 2012).

\section{MYC-SYNTHETIC LETHAL GENES AND THE HALLMARKS OF MYC}

The genome-wide interrogation via these RNAi interference screens has begun to elucidate genes that selectively affect the survival and fitness of cells in the context of oncogenic MYC. To show relevance to cancer, selected MYC-SL genes were tested in cancer cells stratified for MYC levels (Kessler et al. 2012; Liu et al. 2012; Toyoshima et al. 2012). Results were confirmed through independent experiments using different small interfering RNAs (siRNAs) or short hairpins RNAs (shRNAs) to filter off-target effects. Here we discuss MYC-SL genes with respect to known as well as unforeseen MYC-associated functions.

MYC-associated phenotypes can be summarized by core hallmarks, which relate to its biochemical and transcriptional properties. These hallmarks derive from the constitutive activity of MYC functioning as a sequencespecific transcriptional modulator, operating through its binding partner MAX, which is required for high-affinity DNA binding (see Conacci-Sorrell et al. 2014). MYC-MAX heterodimers stimulate activity of all three main RNA polymerases-I, II, and III-and sustain a broad transcriptional program, which leads to cell growth and proliferation in many, if not all, tissue types (see Chappell and Dalton 2013; Hurlin 2013; Campbell and White 2014; Conacci-Sorrell et al. 2014). MYC influences both transcription initiation and elongation complexes through critical protein partners and recruitment of chromatin acetylation complexes (see Conacci-Sorrell et al. 2014; Hann 2014; 
S. Cermelli et al.

Rahl and Young 2014; Sabò and Amati 2014). In addition, by directly interacting with the DNA replication machinery, MYC increases the rate of DNA synthesis (Dominguez-Sola et al. 2007; Robinson et al. 2009). These properties are reflected in prominent hallmarks such as hyperactivity of the protein synthetic apparatus including increased synthesis of ribosomal proteins, rRNAs, and tRNAs (see Campbell and White 2014), and increased activity of metabolic pathways (see Dang 2013; Morrish and Hockenbery 2014). Some of these functions contribute to increased fitness, relative to normal tissues, such as the accelerated proliferative rate, independence from growth and differentiation factors, and an increased propensity for self-renewal (Chappell and Dalton 2013) that collectively give MYC-overexpressing cells a competitive advantage (see Johnston 2014). On the other hand, MYC hyperactivity is accompanied by vulnerabilities that can limit its tumorigenic property and could be exploited for therapeutics. Among the known examples of MYC's Achilles heel are the heightened sensitivity to apoptotic stimuli (Evan and Littlewood 1998), the spontaneous accumulation of DNA damage (see Kuzyk and Mai 2014), and alterations of metabolic pathways (see Dang 2013; Morrish and Hockenbery 2014). These phenotypes are evolutionarily conserved from Drosophila to mammalian cells (see Gallant 2013). Thus, it is not unexpected that at least some MYC-SL genes impinge on these hallmarks.

\section{MYC-SL Networks}

To understand the underlying pathways connecting MYC-SL genes that have been so far identified in three different RNAi screening approaches (400 genes from Kessler, 101 from Toyoshima, and two from Liu) (Kessler et al. 2012; Liu et al. 2012; Toyoshima et al. 2012), we have performed network analyses using a manually curated human interaction database, which was derived from BioGRID, Cancer Cell Map, HPRD, HumanCyc, IMID, IntAct, MINT, NCI-Nature, and Reactome and accessed through Pathway Commons (Cerami et al. 2011). The merging of these databases enabled searching comprehensive human-centric pairwise interactions, which can be verified through PubMed. A subset of MYC-SL genes, identified from the three RNAi screens, can be linked through functional interactions into a single network (of about 100 genes) when a set of "core" genes known to be linked to MYC function is used as a bridge (Fig. 3A,B). To increase the confidence in this analysis, only interactions with two or more PubMed references were considered. Thus, despite the fact that only one gene, BRD4, was found in common between the two large-scale screens of Kessler and Toyoshima, network analysis shows prominent interactions among MYC-SL genes. Three functional hubs can be recognized, as visualized by the circular network in Figure 3A. One includes genes involved in transcription initiation and elongation complexes (Fig. 3AI), the second highlights both positive (TRRAP) and negative regulators (NCOR1) connected to the MYCMAX network (Fig. 3AII), and the third hub includes ubiquitin and sumoylation functions related to cell cycle checkpoint and DNA repair, as well as kinases involved in these processes (Fig. 3AIII). The network layout of Figure 3B allows better visualization of the multiple connections among MYC-SL genes. Below, we discuss components of these hubs that scored as synthetic lethal and refer the reader to O'Shea and Ayer (2013) and Conacci-Sorrell et al. (2014) for a detailed description of MYCMAX and their extended networks.

\section{Transcription Initiation and Elongation Complexes}

Major components of the transcription initiation and RNA polymerase complexes emerged as synthetic lethal genes, highlighting the sensitivity of MYC-overexpressing cells to diminished levels of both general transcription factors and of RNA polymerase subunits, particularly GTF subunits that are components of all three major RNA polymerases (Vannini and Cramer 2012). These findings indicate the dependency of MYC-overexpressing cells on components critical to sustaining cell growth. It is likely that stable inhibition of these protein complexes 
MYC-Driven Cancers

impairs the viability of normal cells, because these genes are involved in basic transcriptional events such as promoter opening (GTF2E2 and GTF2H) and in bridging RNA polymerase complexes to the TATA binding protein, TBP (GTF2B). However, the fact that this functional hub was represented in both screens points to a MYC-dependent vulnerability to "transcriptional stress," perhaps caused by hyperengagement of the transcriptional machinery. Other hits in this class of proteins, such as GTF2H4, are also linked to transcription-coupled DNA repair, emphasizing yet another aspect of vulnerabilities of MYC-overexpressing cells. Basic components of the transcription initiation and elongation complexes and genes that emerged as synthetic lethal are illustrated in Figure 4 (MYC$S L$ in green are from Kessler et al. 2012; MYC-SL in blue are from Toyoshima et al. 2012).

Both screens homed in on BRD4, a critical component of transcription elongation processes, which was recently directly linked to MYC both through a common protein partner PTEFb and also as a regulator of the MYC gene itself (Fig. 4B) (see Rahl and Young 2014). Despite the widespread abundance of BRD4 in many tissues, its bromodomain is a highly druggable moiety required for its function, which renders BRD4 an attractive drug target (see Bradner 2014). It is worth noting that two other

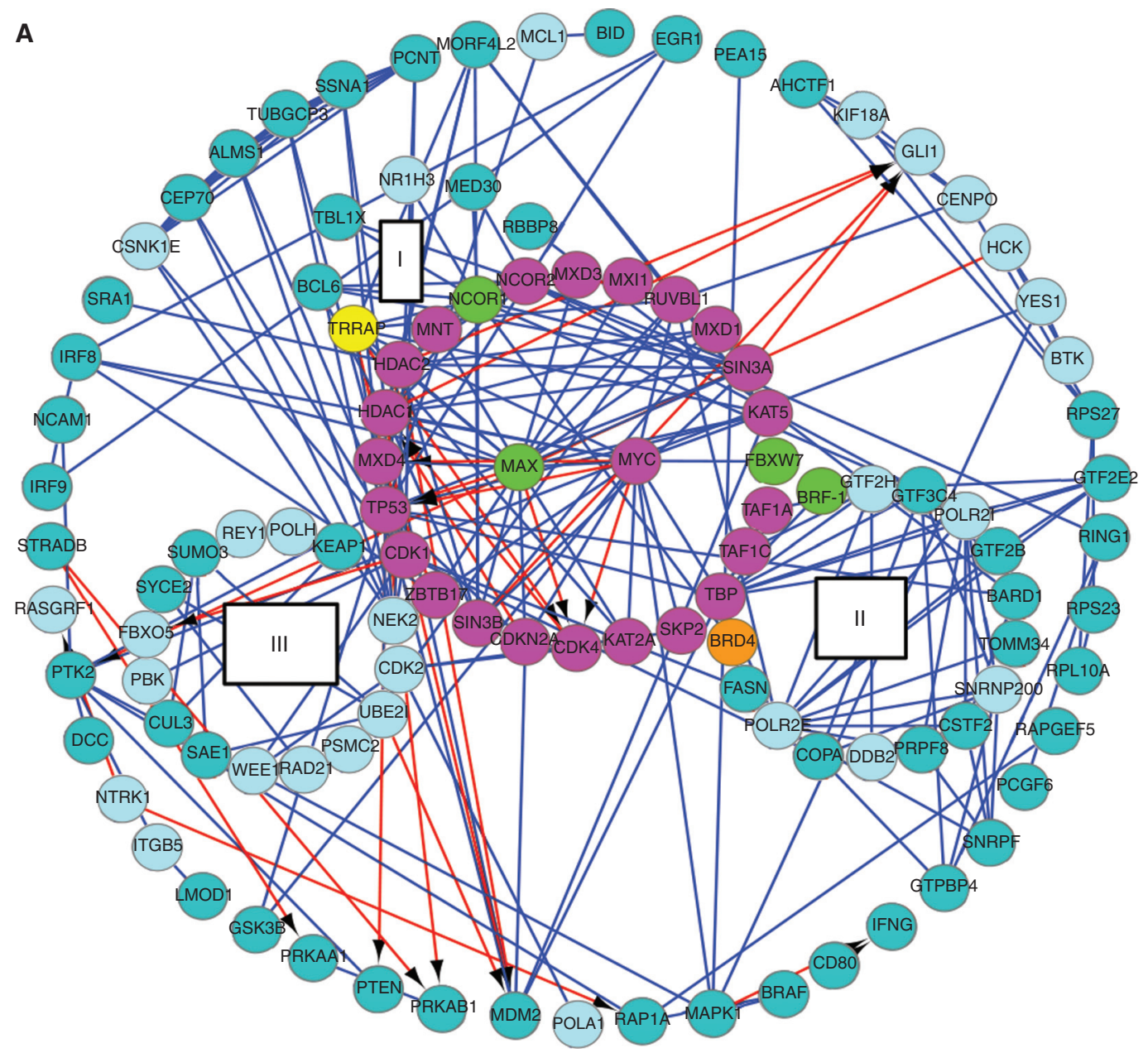

Figure 3. Subset of MYC-SL genes functionally linked through network analysis. (Legend continues on following page.) 
S. Cermelli et al.

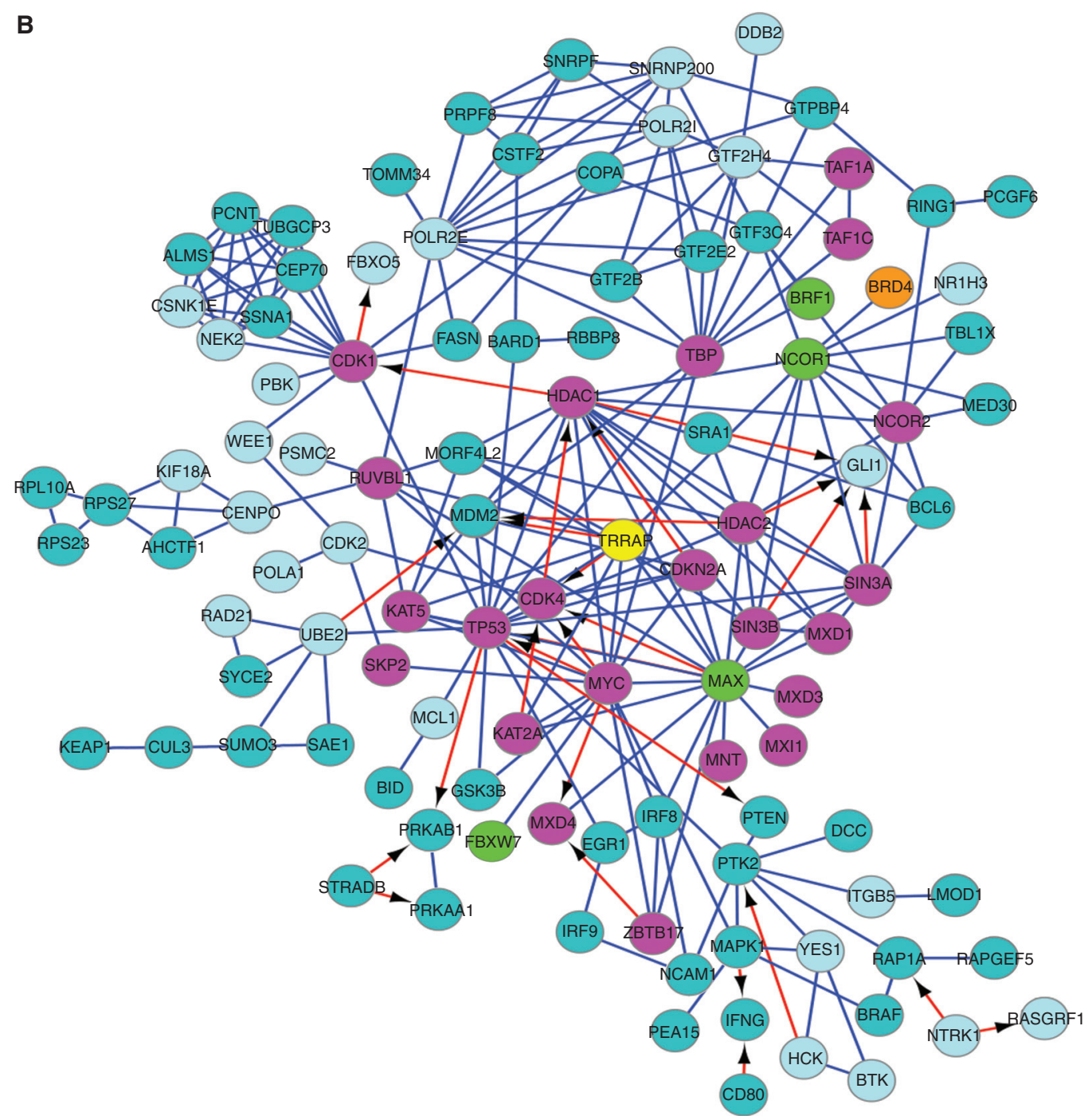

Figure 3. (Continued). Direct interactions among a subset of MYC-SL genes from all screens identified using a manually curated human interaction database derived from the merging of BioGRID, Cancer Cell Map, HPRD, HumanCyc, IMID, IntAct, MINT, NCI-Nature, and Reactome (see text for details). To verify the significance of the number of interactions among this MYC-SL gene network, a permutation randomized networks method was applied (Stumpf and Wiuf 2009), which indicated a $p$ value of $2.841 \times 10^{-07}$ at a $95 \%$ confidence. (Light blue) Toyoshima hits; (dark blue) Kessler hits; (pink) A set of genes known to functionally interact with MYC ("core" genes). MYC-SL genes that intersect between the "core" genes and the Kessler screen (green), between "core" and Toyoshima (yellow), and intersection between Kessler and Toyoshima (orange). Interactions without directionality (blue lines); interactions with known directionality (red lines). Three functional hubs are highlighted in the circular network $(A)$ : One is centered around the MYC-MAX network (I); the second includes components of transcription initiation and elongation complexes, including BRD4 (II); and the third encompasses genes involved in cell cycle checkpoint and DNA-damage repair (III). (B) Organic layout of the same network to better visualize the connections between $M Y C$-SL genes. 
MYC-Driven Cancers
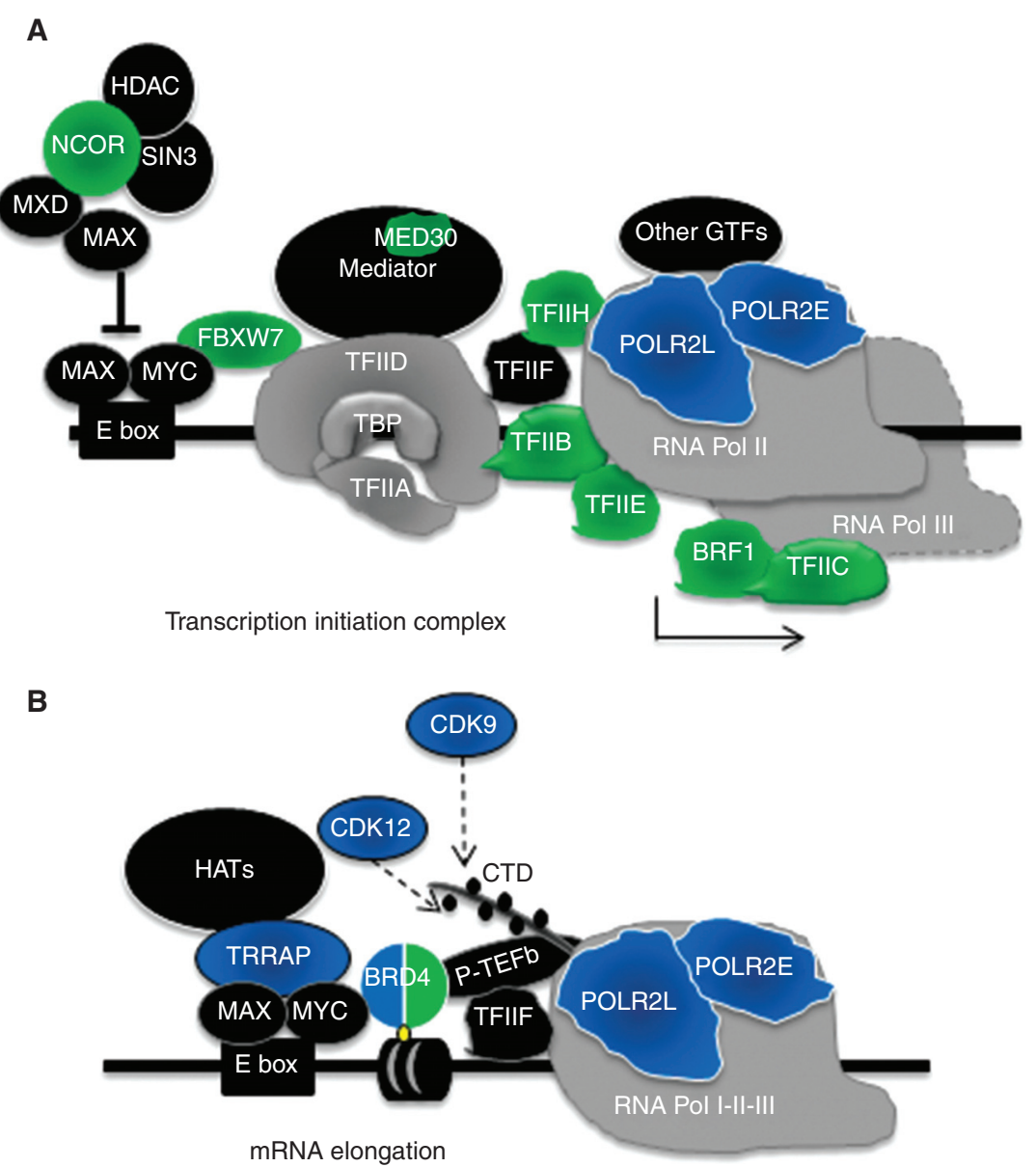

Figure 4. MYC-synthetic lethal genes related to transcription initiation and elongation complexes. $(A)$ Schematic of transcription initiation complexes highlighting $M Y C-S L$ gene products. (B) Schematic of transcription elongation complexes (green, hits from Kessler; blue, hits from Toyoshima). CDK9, with a established role in phosphorylation of RNA polymerase, was identified through an siRNA screen comparing MYCN amplified versus nonamplified neuroblastoma cells (C Grandori, unpubl.).

bromodomain-containing proteins, CECR2 and BARD1, emerged from Toyoshima et al. (2012) and Kessler et al. (2012), respectively, and a third, ATAD2, was identified through a candidate approach in endometrial cancers (Raeder et al. 2013). Although these proteins represent a different class of epigenetic modifiers and are not expected to be targeted by the current BET-family inhibitors (Filippakopoulos et al. 2010), their bromodomains could also be specifically inhibited. Because viral promoters drove expression of MYC in the RNAi screens, it is likely that the mechanism of BRD4synthetic lethality occurs through the transcriptional regulation of genes other than MYC itself. One hypothesis is suggested from the finding that CDK12 was also identified as a MYC-SL gene (Toyoshima et al. 2012). Recently, this kinase was found to regulate transcription elongation following the DNA-damage response (Bartkowiak et al. 2010); thus, deficiency of CDK12 or other elongation factors, such as BRD4, enabling transcription of DNA-repair genes may cripple the capacity of MYC-overex- 
S. Cermelli et al.

pressing cells to cope with DNA replication stress. Indeed, as discussed below, DNA-repair genes are one of the most over-represented functional categories among MYC-SL genes.

Synthetic Dosage Lethality Activators and Repressors Linked to MYC-MAX Networks

MYC activity is tightly controlled in normal cells through the engagement of networks of negative and positive regulators (Hurlin 2013; Wiese et al. 2013; Conacci-Sorrell et al. 2014). Thus, it is not surprising that several MYC protein partners and key regulators have been identified in both screens (Figs. 3 and 4). Positive mediators of MYC function such as TRRAP (Figs. 3B and 4), which recruits histone acetylase complexes, can be readily interpreted as synthetic lethal genes because they are essential mediators of MYC oncogenic functions (McMahon et al. 2000; Nikiforov et al. 2002). However, direct antagonists paradoxically appear to also be synthetic lethal with MYC. This paradox finds an explanation, once again, in yeast genetics from a condition described as "synthetic dosage lethality." This type of genetic interaction was identified from gain-of-function screens (Sopko et al. 2006) in which the lack of a negative regulator directly targeting the protein in question led to pathway hyperactivation. Similarly, because the RNAi screens described herein have been performed using MYC overexpression, as in most cancers, this type of interaction could have been predicted. Synthetic dosage lethality describes a condition in which overexpression of MYC is well tolerated in wild-type cells that have functioning negative regulators but is not tolerated in cancer cells when inactivation of a negative regulator of MYC occurs. For example, the ubiquitin ligase FBXW7 was among MYC-SL genes (Kessler et al. 2012), a finding that can be explained by synthetic dosage lethality. FBWX7 controls ubiquitin-dependent degradation of MYC (Welcker et al. 2004; Popov et al. 2007) and other cell cycle regulators. Loss of FBW7 in MYC overexpressing cells could lead to excessive accumulation of MYC protein leading to cell toxicity. Because loss-of-function muta- tions of $F B W 7$ are frequently observed in cancer, leading to loss of its tumor suppressor function, it would be interesting to assess the mutual exclusivity between $M Y C$ amplification and FBW7 mutations.

Synthetic dosage lethality may also explain NCOR1, a corepressor mediating basal transcriptional activity of classical nuclear receptors, which was a high-confidence hit in the Kessler screen. Repression by complexes that contain NCOR/SMRT (silencing mediator of retinoic acid and a thyroid hormone receptor) is mediated through SIN3A/B and histone deacetylase enzymes (see Conacci-Sorrell et al. 2014). These complexes directly antagonize transcriptional activation by MYC-MAX complexes through the MXD family and MNT, a family of leucine zipper and helix-loop-helix DNA binding proteins, which also heterodimerize with MAX (see Gallant 2013; Hurlin 2013; Conacci-Sorrell et al. 2014). One hypothesis to explain synthetic lethality is that NCOR1 deficiency may lead to unrestricted chromatin acetylation with possible deleterious effects for cell fitness. Yet another example of a MYC antagonist showing synthetic lethality with MYC overexpression is MNT. A recent study of conditional MNT knockout mice showed that MNT deficiency, rather than accelerating, prevents MYC oncogenesis by exacerbating apoptosis (Link et al. 2012). This example provides relevance to potential synthetic dosage lethal interactions in an in vivo setting. Independent evidence obtained from a microRNA overexpression screen identified mir210, a MNT-targeting microRNA, as causing lethality in MYC-overexpressing cells by effectively mimicking MNT knockdown (see Zhang et al. 2009; C Grandori, unpubl.). Finally, a recent finding points to yet another hub of synthetic lethal interactions through the extended MYCMAX network, this time linked to cooperative metabolic functions (P Carroll, D Diolaiti, L McFerrin, and RN Eisenman, unpubl.).

\section{DNA Repair, Cell Cycle, and Checkpoints}

In the genomic-scale screen by Kessler et al. (2012), two SUMO-activation enzymes, SAE1 and SAE2, were among the high-confidence 
hits. Depletion of these enzymes led to a global loss of SUMOylation and accumulation of cells in $\mathrm{G}_{2} / \mathrm{M}$ with abnormal mitotic spindles followed by mitotic catastrophe. These events were associated with impaired expression of MYC-induced spindle-related genes indicating that SUMOylation by SAE1 and SAE2 may influence MYC transcriptional activity toward a selective group of genes (Kessler et al. 2012). Our network analysis shows that SAE1 is linked to two other MYC-SL genes, UBE2l and MDM2 (Fig. 3), and, indeed, SUMOylation has been linked to the DNA-damage response through the MDM2-p53 axis (Lee et al. 2012), perhaps explaining how SAE1-2 knockdown could lead to lethality.

DNA repair and cell cycle checkpoint were the most enriched functional annotations among MYC-SL genes identified in the Toyoshima screen, and experimentally confirmed by a DNA-damage assay for one-third of the genes retested (Toyoshima et al. 2012). Among the MYC-SL genes involved in DNA-repair processes were polymerases with roles in translesion DNA synthesis (POLH and REV1L), an endonuclease (NEIL), mitotic checkpoint genes activated in response to DNA damage (WEE1 and WEE2 that inhibit CDK2 and CDK1 activity), regulators of the mitotic spindle (PRC1), and components of the cohesin complex (RAD21). On the other hand, lowering the levels or activity of CDK1 and CDK2 was previously found to limit the fitness of MYC-overexpressing cells in vitro and in models of MYC tumorigenesis (Goga et al. 2007; Campaner et al. 2009). CDK2 also emerged as MYC-SL in Toyoshima's screen (Fig. 3). Taken together, these results indicate that MYC overexpressing cells are both addicted to checkpoints controlling CDK activity during cell-cycle transitions (such as during $\mathrm{G}_{2} / \mathrm{M}$ through WEE1) and dependent upon elevated CDK activity to drive proliferation and limit cellular senescence (Campaner et al. 2009; Hybring and Larson 2010). One may wonder if MYC-SL interactions related to cell cycle events are shared by other oncogenic pathways, because inhibition of WEE1, for example, has been shown to preferentially impair p53-deficient cancer cells (Bridges et al. 2011). Thus, the absolute specificity of these MYC-SL interactions, for deregulated MYC-expressing cells, remains to be established.

Finally, through a candidate gene approach, the requirement for certain DNA-repair enzymes and S-phase checkpoints has emerged as enablers of MYC-induced tumorigenesis. For example, mutation of the ATR-Seckel syndrome gene blocks emergence of MYC-induced lymphoma and pancreatic cancer in mice, and this genetic interaction is specific, because it does not occur in RAS-driven cancers (Murga et al. 2011). Similarly, the DNA helicase WRN, implicated in repair of DNA replication structures, also shows a synthetic lethal interaction with oncogenic MYC, both in vitro (Robinson et al. 2009) and in MYC-driven lymphomagenesis (Moser et al. 2012).

Although WRN and ATR were not identified in the current screens, possibly because of the inefficient siRNA-mediated knockdown of these genes (C Grandori, unpubl.), the previously described dependencies further confirm the requirement of MYC overexpressing cells upon intact DNA-replication-repair sensors.

\section{Growth, Metabolism, and Apoptosis}

The evidence that MYC transcriptional targets relate to the regulation of cell growth (see Campbell and White 2014) and metabolism (see Dang 2013; Morrish and Hockenbery 2014) is overwhelming. Yet, this aspect was not prominently revealed through the screens performed to date, with the exception of Liu et al. (2012), who identified two kinases, ARK5 and AMPK, as synthetic lethal with MYC-ER activation in a human osteosarcoma cell line (U2OS). ARK5 and its downstream target AMPK negatively regulate the mammalian target of rapamycin (mTORC1), thereby inhibiting protein synthesis. This finding may again fit with the model of synthetic dosage effect, because abrogation of this potential break on a parallel protein synthesis pathway leads MYC-overexpressing cells to effectively burn through their energetic reserves and elicit an apoptotic response. Other targets identified in Toyoshima's screen were ALDO A and PDK, both enzymes involved in 
S. Cermelli et al.

metabolic pathways, which have been well shown to be affected by the MAX network (see Dang 2013; O’Shea and Ayer 2013). The surprising paucity of targets involved in cell growth and metabolic pathways, with the exceptions mentioned above, indicates the possibility that their knockdown could be detrimental to normally proliferating cells. For example, knockdown of DDX18, an RNA helicase involved in ribosomal biogenesis whose transcription is stimulated by MYC (Grandori et al. 1996), was significantly toxic to normal cells, and, accordingly, DDX18 was filtered out in the selection of MYC-SL genes. Similarly, although the eukaryotic initiation factor 4E (eIF4e) was shown to impair MYC-induced tumorigenesis, its inhibition also has profound, albeit reversible, effects on normal somatic tissues (Lin et al. 2012). A related gene, eIF4E2, however, was among the $M Y C-S L$ genes in Kessler's screen.

A still largely unanswered question is the relation between MYC-SL genes and the MYC transcriptional program. A preliminary comparison of MYC-SL genes with the MYC target gene database (Zeller et al. 2003) indicated a small but statistically significant overlap. In addition, three genes that showed robust synthetic lethal interactions across tissues-PES-1, CECR2, and CSNK1e (Toyoshima et al. 2012) all harbor multiple consensus MYC-MAX binding sites within their promoter regions, suggesting a possible direct relation to MYC. Tissue-specific transcriptional effects caused by MYC will require this analysis to be tailored to specific cancer types.

\section{NOVEL PATHWAYS CONTRIBUTING TO THE FITNESS OF MYC-HYPERACTIVATED CELLS IDENTIFIED THROUGH SYNTHETIC LETHALITY}

\section{Kinases and Developmental Pathways}

Several kinases emerged from the RNAi screens, potentially providing a set of highly druggable targets. Among these, HCK and CSNK1e were independently identified as signaling molecules that significantly affected MYC transcriptional targets by using a computational method for the genome-wide identification of posttranslational modulators of transcription factor activity (MINDy) (Wang et al. 2009). The fact that two completely different approaches, that is, prediction-based and experiment-based, pointed to these kinases suggests that they represent key targets that affect MYC-driven cancers. Mechanistically, the role of these kinases remains unclear. For example, although previous literature identifies CSNK1e as a modulator of circadian rhythms (Preuss et al. 2004; Badura et al. 2007; Meng et al. 2008), more recent studies do not confirm its essential role in this pathway (Sekine et al. 2008; Walton et al. 2009). In contrast, CSNK1e has been implicated in cancer, both in ovarian (Rodriguez et al. 2012) and in breast cancer, where its function is linked to the activity of the WNT pathway (Kim et al.). CSNK1e has also been shown to be required for transcriptional response to Hedgehog $(\mathrm{HH})$ signaling (Varjosalo et al. 2008), and in this respect, it is worthwhile to point out that GLI1, the main transcriptional mediator of $\mathrm{HH}$ signaling, also emerged as a MYC-SL gene. This indicates that both developmental pathways, WNT and $\mathrm{HH}$, may play relevant roles to support MYC-mediated tumorigenesis (Roussel and Robinson 2013). Another novel target with a potential developmental role is the human homolog of Pescadillo, PES1, a gene discovered in zebrafish embryonic development that, as discussed above, might be a direct target of MYC transcriptional regulation. PES-1 contains a BRCT domain, which is an essential region for several genes involved in DNA repair, including the $B R C A 1$ gene. It has been proposed that PES-1 influences folding of large chromatin domains via its BRCT domain (Zhang et al. 2005). PES-1 has also been linked to rRNA synthesis (Holzel et al. 2007). Interestingly, its knockdown in neuroblastoma leads both to cell death and differentiation ( $\mathrm{M}$ Toyoshima and C Grandori, unpubl.). Because MYC overexpression impairs responses to differentiation signals, PES-1 may be linked to this hallmark activity of MYC, and given the potential druggability of BRCT domains, should be further explored as a therapeutic target (Simeonov et al. 2008). 
MYC-Driven Cancers

\section{CHALLENGES AHEAD}

\section{How to Define a Cancer as MYC-Driven}

Currently, with the exception of Burkitt's lymphoma and neuroblastoma, MYC status is not a biomarker used in the clinic. Because MYC is generally not mutated, but rather its expression is deregulated through multiple mechanisms, the identification of surrogate biomarkers of MYC deregulation is challenging but much needed if we plan to develop therapeutic agents selective for cells with hyperactive MYC. Numerous studies have reported amplification or overexpression of MYC in solid tumors, such as breast (Berns et al. 1992; Blancato et al. 2004; Bouchalova et al. 2009), ovarian (Darcy et al. 2009), colon (Al-Kuraya et al. 2007), prostate (Sato et al. 2006), lung (Kim et al. 2006), and others. However there is great variation in the prognostic significance and type of alterations detected (gene amplification and overexpres- sion) between the different studies, emphasizing the lack of unambiguous markers. The recent availability of large controlled data sets across multiple cancer types from The Cancer Genome Atlas (TCGA) may allow a more accurate evaluation of MYC family alterations by examining the significance of copy number aberrations and mRNA expression in primary human tumor samples. For example, our recent cross-cancer comparison of the frequency of MYC copy number gain or amplification (limited to c-MYC and not inclusive of MYCN or MYCL) using data available in the TCGA implicates MYC in multiple cancer types and, in particular, in ovarian and breast cancers (Fig. 5). However, because MYC copy number is not always the best predictor of MYC expression, a confident estimation of the extent to which the MYC pathway is not only amplified, but also active, will require additional investigation.

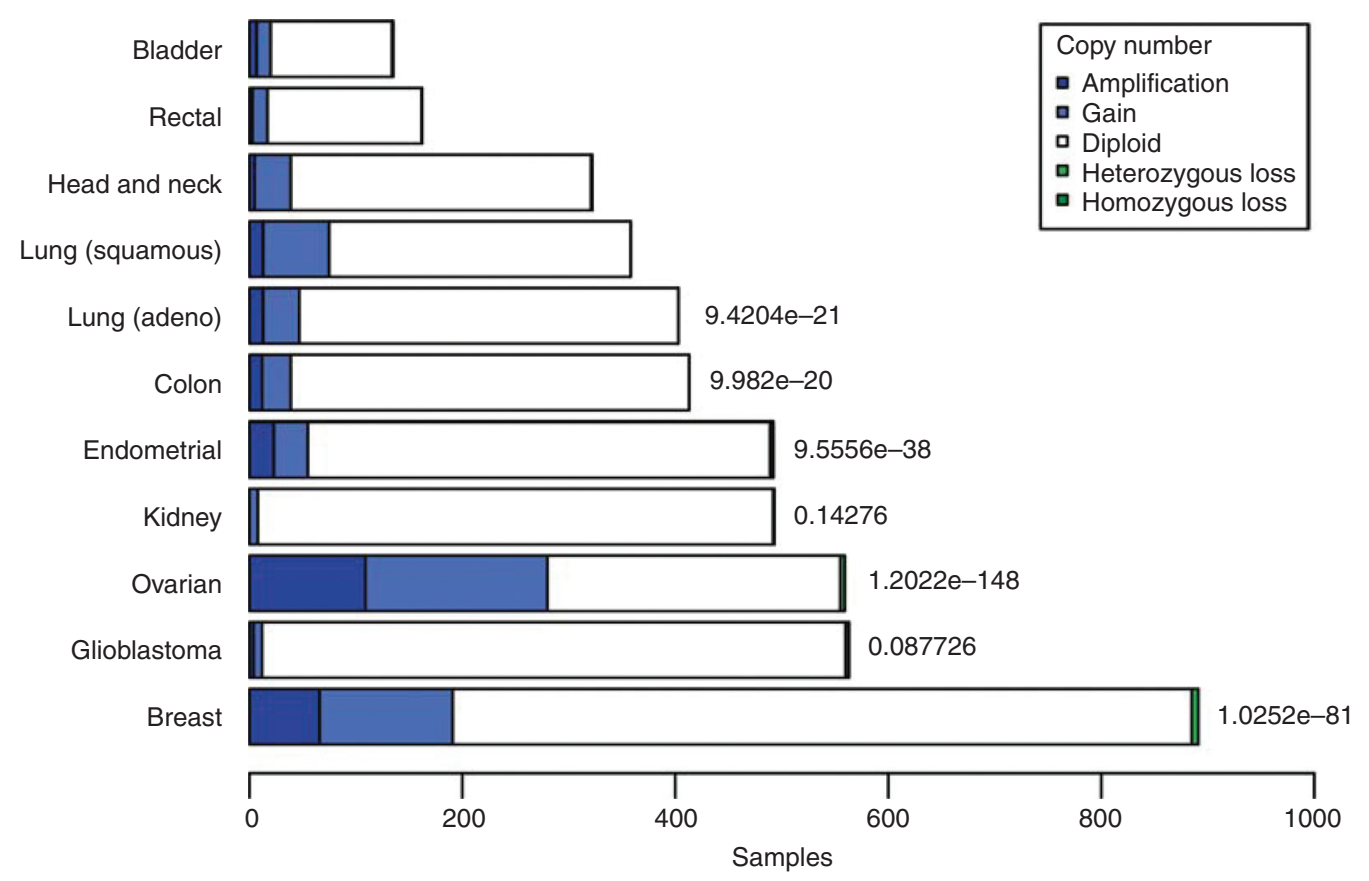

Figure 5. MYC copy number values in a subset of TCGA tumor types. This chart illustrates a recent analysis of The Cancer Genome Atlas data set relating to alterations in gene copy number for c-MYC across different cancer types. Gain indicates copy number change between 0.5 and 1.5 ; amplification is copy number change $>1.5$ (numbers reported are continuous, not integer, and may capture subclonality of copy number events). The number to the right of each bar is the GISTIC $q$ value for significance (Beroukhim et al. 2007) of MYC copy number where available. 
S. Cermelli et al.

Through an unbiased genome-wide approach, it may be possible to identify expression patterns that distinguish MYC-overexpressing cancers from other cancers within the same tissue. Alternatively, MYC gene expression signatures derived from genetic manipulations of MYC levels could be used through a candidate gene approach. Also, because deregulation of different members of the MYC family, such as MYCN or MYCL, may have different functional consequences and characteristic biomarkers, a distinction based on which family member is altered should be taken into account. In fact, expression of exogenous MYC or MYCN in the same neural progenitors has very different outcomes, with different cell lineages emerging (Roussel and Robinson 2013). Overall, much work is still needed in this area to arrive at candidate genes or gene products that unambiguously classify MYC-driven cancers. These novel molecular markers should then be linked to existing clinical and pathological criteria to enable efficacious selection of patients for treatment.

\section{Are MYC Synthetic Lethal Interactions Conserved across Cancer Types as Well as Modes of MYC Deregulation?}

Despite the limited data available to date, a cross-cancer comparison indicates that synthetic lethal interactions may be shared between different tissues. This preliminary conclusion is derived from the identification of common $M Y C$ SL among breast cancer (Kessler et al. 2012), neuroblastoma, and ovarian cancers ( $\mathrm{M}$ Toyoshima and C Grandori, unpubl.). Among these are CSNK1e, CECR2, and PES1. In addition, BRD4 was identified in breast cancer cells in the Kessler screen and in the isogenic HFF system (Toyoshima et al. 2012). Also ARK-5, which was originally identified in an osteosarcoma cell line, was validated in a hepatoblastoma model (Liu et al. 2012). Based on these, albeit sparse, bits of evidence, it is possible that there will be shared synthetic lethal pathways between different tissue types. However, MYC-SL interactions in vitro were obtained through artificial overexpression systems, and it is possible that SL interactions in cancer may also reflect the causes of
MYC deregulation. For example, the dependence on BRD4 of cancer cells may occur through different mechanisms, one through its effect on the regulation of the MYC gene itself as shown in models of leukemia, which are dependent on expression of MYC without structural alterations of the MYC gene (Zuber et al. 2011). The other, when MYC overexpression is consequent to structural changes such as gene amplification or gene translocations, the requirement for BRD4 may reflect its role in transcription of other genes. Distinction of SL interactions based on the types of MYC deregulation remains to be established and perhaps best addressed by performing RNAi screens in cancer cells with defined alterations of MYC.

\section{Specificity of MYC-SL Genes in the Context} of the Cancer Genome

MYC-SL genes were defined in isogenic and genetically engineered systems and validated in a limited number of cancer cells. Therefore, we need to remain aware that the specificity of these SL interactions for MYC-driven tumors has not been unequivocally established. Indeed, it is still possible that certain $M Y C-S L$ interactions might be broader transformation-related synthetic lethal interactions. A careful cross-oncogene comparative analysis, preferably within an isogenic system, should be performed. Finally, in human tumors, multiple genetic lesions coexist. Thus, the impact of multiple mutations or epigenetic alterations is likely to affect synthetic lethal interactions, and we should keep an open mind when validating MYC-SL genes. However, the fact that selective $M Y C-S L$ genes identified in isogenic systems have been confirmed in the context of cancer cells is encouraging. Challenges in the validation pipeline also include determining which in vitro or in vivo model might be more suitable for predicting the efficacy of $M Y C-S L$ genes as cancer drug targets.

Exploiting MYC-Synthetic Lethal Interactions for Cancer Therapy

If we wish to translate synthetic lethal screens to the clinic, rather than allowing them to languish 
in the obscurity of scientific publications, much effort will be needed to prioritize MYC-SL genes with therapeutic potential. This selection should be based not only on their validation in a cancer cell context or through integration of genomics data, but should also be based on their "druggability." For example, we have highlighted potential targets such as kinases and other molecules that harbor domains accessible by small molecule inhibitors, such as bromodomains and BRCT domains. Cell-surface proteins that can be targeted using antibodies or small-protein moieties should also be high on the list of druggable targets. Furthermore, experiments evaluating the rescue of lethality by specific mutant proteins, as through mutations in the ATP binding site for kinases, should be performed because inhibition of protein activity may not be equivalent to the loss of its expression. Thus, much remains to be done before a given MYC-SL gene is proposed as a therapeutic target. Finally, improving communication between academia and industry would facilitate obtaining inhibitors, even as tool compounds, to test their effects in isogenic and cancer cell contexts. In summary, accelerating the process from the bench to the clinic requires a multidisciplinary effort among cancer biologists, bioinformaticians, chemists, and structural biologists. It is also important at early stages to work in close collaboration with clinical oncologists to guide choices of possible drug combinations and to facilitate matching molecular features with clinical characteristics, both of which are relevant to determining appropriate treatments.

Despite these challenges and the complex scenarios of the cancer landscape, synthetic lethal screens provide an approach that promises to facilitate targeting "undruggable" oncogenes, such as MYC, and to enable the functional dissection of genomic information.

\section{ACKNOWLEDGMENTS}

We thank the members of the Grandori laboratory and, in particular, Masafumi Toyoshima, whose contribution toward validating $M Y C$ $S L$ genes was invaluable. We also thank members of the Eisenman laboratory, Daniel Dio- laiti, and Patrick Carroll for helpful discussions during the preparation of this manuscript. We are indebted to Bob Eisenman and Christopher Kemp for critically reviewing this manuscript and Hamid Bolouri for models of the role of CSNK1e in WNT and HH signaling. C.G. is supported by a pilot grant from the Fred Hutchinson Cancer Consortium NCI P30 CA015704, and a Developmental Research Program award from the Pacific Ovarian Cancer Research Consortium; I.S.J. is supported by grant U54CA149237 from the Integrative Cancer Biology Program of the National Cancer Institute. B.B. is supported by the U24CA143835 grant award from the National Cancer Institute. We are also grateful to Jim Watson for his interest in MYC and enabling the MYC scientific community to gather at Cold Spring Harbor in November 2011, where many new connections and ideas discussed here were born. Finally, we thank Bob Eisenman and Chi Dang for making it all happen.

\section{REFERENCES}

${ }^{*}$ Reference is also in this collection.

Al-Kuraya K, Novotny H, Bavi P, Siraj AK, Uddin S, Ezzat A, Sanea NA, Al-Dayel F, Al-Mana H, Sheikh SS, et al. 2007. HER2, TOP2A, CCND1, EGFR and C-MYC oncogene amplification in colorectal cancer. J Clin Pathol 60: $768-772$.

Amati B, Alevizopoulos K, Vlach J. 1998. Myc and the cell cycle. Front Biosci 3: D250-D268.

Badura L, Swanson T, Adamowicz W, Adams J, Cianfrogna J, Fisher K, Holland J, Kleiman R, Nelson F, Reynolds L, et al. 2007. An inhibitor of casein kinase I $\varepsilon$ induces phase delays in circadian rhythms under free-running and entrained conditions. J Pharmacol Exp Ther 322: 730-738.

Bartkowiak B, Liu P, Phatnani HP, Fuda NJ, Cooper JJ, Price DH, Adelman K, Lis JT, Greenleaf AL. 2010. CDK12 is a transcription elongation-associated CTD kinase, the metazoan ortholog of yeast Ctk1. Genes Dev 24: $2303-$ 2316.

Benanti JA, Galloway DA. 2004. Normal human fibroblasts are resistant to RAS-induced senescence. Mol Cell Biol 24: 2842-2852.

Benanti JA, Wang ML, Myers HE, Robinson KL, Grandori C, Galloway DA. 2007. Epigenetic down-regulation of ARF expression is a selection step in immortalization of human fibroblasts by c-Myc. Mol Cancer Res 5: 11811189.

Berns EM, Klijn JG, van Putten WL, van Staveren IL, Portengen H, Foekens JA. 1992. c-myc amplification is a 
S. Cermelli et al.

better prognostic factor than HER2/neu amplification in primary breast cancer. Cancer Res 52: 1107-1113.

Beroukhim R, Getz G, Nghiemphu L, Barretina J, Hsueh T, Linhart D, Vivanco I, Lee JC, Huang JH, Alexander S, et al. 2007. Assessing the significance of chromosomal aberrations in cancer: Methodology and application to glioma. Proc Natl Acad Sci 104: 20007-20012.

Blakely K, Ketela T, Moffat J. 2011. Pooled lentiviral shRNA screening for functional genomics in mammalian cells. Methods Mol Biol 781: 161-182.

Blancato J, Singh B, Liu A, Liao DJ, Dickson RB. 2004. Correlation of amplification and overexpression of the $c-m y c$ oncogene in high-grade breast cancer: FISH, in situ hybridisation and immunohistochemical analyses. Br J Cancer 90: 1612-1619.

Bouchalova K, Cizkova M, Cwiertka K, Trojanec R, Hajduch M. 2009. Triple negative breast cancer-Current status and prospective targeted treatment based on HER1 (EGFR), TOP2A and C-MYC gene assessment. Biomed Pap Med Fac Univ Palacky Olomouc Czech Repub 153: 1317.

* Bradner J. 2014. Inhibiting Myc. Cold Spring Harb Perspect Med doi: 10.1101/cshperspect.a014266.

Bridges KA, Hirai H, Buser CA, Brooks C, Liu H, Buchholz TA, Molkentine JM, Mason KA, Meyn RE. 2011. MK1775, a novel Weel kinase inhibitor, radiosensitizes p53-defective human tumor cells. Clin Cancer Res 17: 5638-5648.

Campaner S, Doni M, Hydbring P, Verrecchia A, Bianchi L, Sardella D, Schleker T, Perna D, Tronnersjo S, Murga M, et al. 2009. Cdk2 suppresses cellular senescence induced by the c-myc oncogene. Nat Cell Biol 12: 54-59.

* Campbell KJ, White RJ. 2014. MYC regulation of cell growth through control of transcription by RNA polymerase I and III. Cold Spring Harb Perspect Med doi: 10.1101/ cshperspect.a018408.

Cerami EG, Gross BE, Demir E, Rodchenkov I, Babur O, Anwar N, Schultz N, Bader GD, Sander C. 2011. Pathway Commons, a web resource for biological pathway data. Nucleic Acids Res 39: D685-D690.

* Chappell J, Dalton S. 2013. Roles for MYC in the establishment and maintenance of pluripotency. Cold Spring Harb Perspect Med 3: a014381.

Chung N, Locco L, Huff KW, Bartz S, Linsley PS, Ferrer M, Strulovici B. 2008. An efficient and fully automated highthroughput transfection method for genome-scale siRNA screens. J Biomol Screen 13: 142-148.

* Conacci-Sorrell M, McFerrin L, Eisenman RN. 2014. An overview of MYC and its interactome. Cold Spring Harb Perspect Med 4: a014357.

Costanzo M, Baryshnikova A, VanderSluis B, Andrews B, Myers CL, Boone C. 2012. Genetic networks. In Handbook of systems biology - Concepts and insights (ed. Walhout M, et al.), pp. 115-136. Academic, San Diego.

* Dang CV. 2013. MYC, metabolism, cell growth, and tumorigenesis. Cold Spring Harb Perspect Med 3: a014217.

Darcy KM, Brady WE, Blancato JK, Dickson RB, Hoskins WJ, McGuire WP, Birrer MJ. 2009. Prognostic relevance of c-MYC gene amplification and polysomy for chromosome 8 in suboptimally-resected, advanced stage epithe- lial ovarian cancers: A Gynecologic Oncology Group study. Gynecol Oncol 114: 472-479.

Dixon SJ, Costanzo M, Baryshnikova A, Andrews B, Boone C. 2009. Systematic mapping of genetic interaction networks. Ann Rev Genet 43: 601-625.

Dominguez-Sola D, Ying CY, Grandori C, Ruggiero L, Chen B, Li M, Galloway DA, Gu W, Gautier J, Dalla-Favera R. 2007. Non-transcriptional control of DNA replication by c-Myc. Nature 448: 445-451.

Eilers M, Picard D, Yamamoto KR, Bishop JM. 1989. Chimaeras of myc oncoprotein and steroid receptors cause hormone-dependent transformation of cells. Nature 340: 66-68.

Evan G, Littlewood T. 1998. A matter of life and cell death. Science 281: 1317-1322.

Filippakopoulos P, Qi J, Picaud S, Shen Y, Smith WB, Fedorov O, Morse EM, Keates T, Hickman TT, Felletar I, et al. 2010. Selective inhibition of BET bromodomains. Nature 468: 1067-1073.

Fong PC, Boss DS, Yap TA, Tutt A, Wu P, Mergui-Roelvink M, Mortimer P, Swaisland H, Lau A, O'Connor MJ, et al. 2009. Inhibition of poly(ADP-ribose) polymerase in tumors from BRCA mutation carriers. $N$ Engl J Med 361: $123-134$.

* Gallant P. 2013. Myc function in Drosophila. Cold Spring Harb Perspect Med 3: a014324.

Goga A, Yang D, Tward AD, Morgan DO, Bishop JM. 2007. Inhibition of CDK1 as a potential therapy for tumors over-expressing MYC. Nat Med 13: 820-827.

Grandori C. 2013. A high throughput siRNA screening platform to identify MYC-synthetic lethal genes as candidate therapeutic targets. Methods Mol Biol 1012: 187-200.

Grandori C, Mac J, Siebelt F, Ayer DE, Eisenman RN. 1996. Myc-Max heterodimers activate a DEAD box gene and interact with multiple $\mathrm{E}$ box-related sites in vivo. $E M B O$ 15: 4344-4357.

Grandori C, Gomez-Roman N, Felton-Edkins ZA, Ngouenet C, Galloway DA, Eisenman RN, White RJ. 2005. cMyc binds to human ribosomal DNA and stimulates transcription of rRNA genes by RNA polymerase I. Nat Cell Biol 7: 311-318.

Gurley KE, Kemp CJ. 2001. Synthetic lethality between mutation in Atm and DNA-PK $\mathrm{CS}_{\mathrm{cS}}$ during murine embryogenesis. Curr Biol 11: 191-194.

* Hann SR. 2014. Myc protein interactions. Cold Spring Harb Perspect Med doi: 10.1101/cshperspect.a014399.

Hartwell LH, Szankasi P, Roberts CJ, Murray AW, Friend SH. 1997. Integrating genetic approaches into the discovery of anticancer drugs. Science 278: 1064-1068.

Holzel M, Grimm T, Rohrmoser M, Malamoussi A, Harasim T, Gruber-Eber A, Kremmer E, Eick D. 2007. The BRCT domain of mammalian Pes1 is crucial for nucleolar localization and rRNA processing. Nucleic Acids Res 35: 789-800.

Hu G, Kim J, Xu Q, Leng Y, Orkin SH, Elledge SJ. 2009. A genome-wide RNAi screen identifies a new transcriptional module required for self-renewal. Genes Dev 23: 837-848.

* Hurlin PJ. 2013. Control of vertebrate development by MYC. Cold Spring Harb Perspect Med 3: a014332. 
Hydbring P, Larsson LG. 2010. Tipping the balance: Cdk2 enables Myc to suppress senescence. Cancer Res 70: 6687-6691.

* Johnston LA. 2014. Socializing with Myc: Cell competition in development and as a model for premalignant cancer. Cold Spring Harb Perspect Med doi: 10.1101/cshperspect.a014274.

Kessler JD, Kahle KT, Sun T, Meerbrey KL, Schlabach MR, Schmitt EM, Skinner SO, Xu Q, Li MZ, Hartman ZC, et al. 2012. A SUMOylation-dependent transcriptional subprogram is required for Myc-driven tumorigenesis. Science 335: 348-353.

Kim YH, Girard L, Giacomini CP, Wang P, Hernandez-Boussard T, Tibshirani R, Minna JD, Pollack JR. 2006. Combined microarray analysis of small cell lung cancer reveals altered apoptotic balance and distinct expression signatures of MYC family gene amplification. Oncogene 25: $130-138$.

Kim SY, Dunn IF, Firestein R, Gupta P, Wardwell L, Repich K, Schinzel AC, Wittner B, Silver SJ, Root DE, et al. 2010. CK1 $\varepsilon$ is required for breast cancers dependent on $\beta$-catenin activity. PLoS ONE 5: e8979.

* Kuzyk A, Mai S. 2014. c-MYC-induced genomic instability. Cold Spring Harb Perspect Med doi: 10.1101/cshper spect.a014373.

Lee SW, Lee MH, Park JH, Kang SH, Yoo HM, Ka SH, Oh YM, Jeon YJ, Chung CH. 2012. SUMOylation of hnRNP$\mathrm{K}$ is required for $\mathrm{p} 53$-mediated cell-cycle arrest in response to DNA damage. EMBO J 31: 4441-4452.

Lin CJ, Nasr Z, Premsrirut PK, Porco JA Jr, Hippo Y, Lowe SW, Pelletier J. 2012. Targeting synthetic lethal interactions between Myc and the eIF4F complex impedes tumorigenesis. Cell Rep 1: 325-333.

Link JM, Ota S, Zhou ZQ, Daniel CJ, Sears RC, Hurlin PJ. 2012. A critical role for Mnt in Myc-driven T-cell proliferation and oncogenesis. Proc Natl Acad Sci 109: 1968519690.

Liu L, Ulbrich J, Muller J, Wustefeld T, Aeberhard L, Kress TR, Muthalagu N, Rycak L, Rudalska R, Moll R, et al. 2012. Deregulated MYC expression induces dependence upon AMPK-related kinase 5. Nature 483: 608-612.

McCabe N, Lord CJ, Tutt AN, Martin NM, Smith GC, Ashworth A. 2005. BRCA2-deficient CAPAN-1 cells are extremely sensitive to the inhibition of Poly (ADP-Ribose) polymerase: An issue of potency. Cancer Biol Ther 4: 934-936.

McMahon SB, Wood MA, Cole MD. 2000. The essential cofactor TRRAP recruits the histone acetyltransferase hGCN5 to c-Myc. Mol Cell Biol 20: 556-562.

Meng QJ, Logunova L, Maywood ES, Gallego M, Lebiecki J, Brown TM, Sladek M, Semikhodskii AS, Glossop NR, Piggins HD, et al. 2008. Setting clock speed in mammals: The CK1 $\varepsilon \tau$ mutation in mice accelerates circadian pacemakers by selectively destabilizing PERIOD proteins. Neuron 58: 78-88.

* Morrish F, Hockenbery D. 2014. Myc and mitochondrial biogenesis. Cold Spring Harb Perspect Med doi: 10 1101/cshperspect.a014225.

Moser R, Toyoshima M, Robinson K, Gurley KE, Howie HL, Davison J, Morgan M, Kemp CJ, Grandori C. 2012. MYCdriven tumorigenesis is inhibited by WRN syndrome gene deficiency. Mol Cancer Res 10: 535-545.
Murga M, Campaner S, Lopez-Contreras AJ, Toledo LI, Soria R, Montana MF, D’Artista L, Schleker T, Guerra C, Garcia E, et al. 2011. Exploiting oncogene-induced replicative stress for the selective killing of Myc-driven tumors. Nat Struct Mol Biol 18: 1331-1335.

Nesbit CE, Tersak JM, Prochownik EV. 1999. MYC oncogenes and human neoplastic disease. Oncogene 18: 30043016.

Nikiforov MA, Chandriani S, Park J, Kotenko I, Matheos D, Johnsson A, McMahon SB, Cole MD. 2002. TRRAP-dependent and TRRAP-independent transcriptional activation by Myc family oncoproteins. Mol Cell Biol 22: 5054-5063.

* O’Shea JM, Ayer DE. 2013. Coordination of nutrient availability and utilization by MAX- and MLX-centered transcription networks. Cold Spring Harb Perspect Med 3: a014258.

Paddison PJ, Silva JM, Conklin DS, Schlabach M, Li M, Aruleba S, Balija V, O’Shaughnessy A, Gnoj L, Scobie K, et al. 2004. A resource for large-scale RNA-interferencebased screens in mammals. Nature 428: 427-431.

Popov N, Herold S, Llamazares M, Schulein C, Eilers M. 2007. Fbw7 and Usp28 regulate Myc protein stability in response to DNA damage. Cell Cycle 6: 2327-2331.

Preuss F, Fan JY, Kalive M, Bao S, Schuenemann E, Bjes ES, Price JL. 2004. Drosophila doubletime mutations which either shorten or lengthen the period of circadian rhythms decrease the protein kinase activity of casein kinase I. Mol Cell Biol 24: 886-898.

Raeder MB, Birkeland E, Trovik J, Krakstad C, Shehata S, Schumacher S, Zack TI, Krohn A, Werner HM, Moody SE, et al. 2013. Integrated genomic analysis of the 8q24 amplification in endometrial cancers identifies ATAD2 as essential to MYC-dependent cancers. PLoS ONE 8: e54873.

* Rahl PB, Young RA. 2014. Myc and transcription elongation. Cold Spring Harb Perspect Med doi: 10.1101/cshper sect.a014340.

Robinson K, Asawachaicharn N, Galloway DA, Grandori C. 2009. c-Myc accelerates S-phase and requires WRN to avoid replication stress. PLoS ONE 4: e5951.

Rodriguez N, Yang J, Hasselblatt K, Liu S, Zhou Y, RauhHain JA, Ng SK, Choi PW, Fong WP, Agar NY, et al. 2012. Casein kinase I $\varepsilon$ interacts with mitochondrial proteins for the growth and survival of human ovarian cancer cells. EMBO Mol Med 4: 952-963.

* Roussel MF, Robinson GW. 2013. Role of MYC in medulloblastoma. Cold Spring Harb Perspect Med 3: a014308.

* Sabò A, Amati B. 2014. Gemone recognition by Myc. Cold Spring Harb Perspect Med doi: 10.1101/cshperspect. a014191.

Sato H, Minei S, Hachiya T, Yoshida T, Takimoto Y. 2006. Fluorescence in situ hybridization analysis of c-myc amplification in stage TNM prostate cancer in Japanese patients. Int J Urol 13: 761-766.

Sekine T, Yamaguchi T, Hamano K, Young MW, Shimoda M, Saez L. 2008. Casein kinase Iع does not rescue doubletime function in Drosophila despite evolutionarily conserved roles in the circadian clock. J Biol Rhythms 23: $3-15$.

Simeonov A, Yasgar A, Jadhav A, Lokesh GL, Klumpp C, Michael S, Austin CP, Natarajan A, Inglese J. 2008. Dual- 
S. Cermelli et al.

fluorophore quantitative high-throughput screen for inhibitors of BRCT-phosphoprotein interaction. Anal Biochem 375: 60-70.

Sopko R, Huang D, Preston N, Chua G, Papp B, Kafadar K, Snyder M, Oliver SG, Cyert M, Hughes TR, et al. 2006. Mapping pathways and phenotypes by systematic gene overexpression. Mol Cell 21: 319-330.

Stumpf M, Wiuf C, eds. 2009. Statistical and evolutionary analysis of biological networks. Imperial College Press, London.

Toyoshima M, Howie HL, Imakura M, Walsh RM, Annis JE, Chang AN, Frazier J, Chau BN, Loboda A, Linsley PS, et al. 2012. Functional genomics identifies therapeutic targets for MYC-driven cancer. Proc Natl Acad Sci 109: 9545-9550.

Vannini A, Cramer P. 2012. Conservation between the RNA polymerase I, II, and III transcription initiation machineries. Mol Cell 45: 439-446.

Varjosalo M, Bjorklund M, Cheng F, Syvanen H, Kivioja T, Kilpinen S, Sun Z, Kallioniemi O, Stunnenberg HG, He WW, et al. 2008. Application of active and kinase-deficient kinome collection for identification of kinases regulating Hedgehog signaling. Cell 133: 537-548.

Walton KM, Fisher K, Rubitski D, Marconi M, Meng QJ, Sladek M, Adams J, Bass M, Chandrasekaran R, Butler T, et al. 2009. Selective inhibition of casein kinase $1 \varepsilon$ minimally alters circadian clock period. J Pharmacol Exp Ther 330: 430-439.

Wang K, Saito M, Bisikirska BC, Alvarez MJ, Lim WK, Rajbhandari P, Shen Q, Nemenman I, Basso K, Margolin AA, et al. 2009. Genome-wide identification of post- translational modulators of transcription factor activity in human B cells. Nat Biotechnol 27: 829-839.

Wang ML, Walsh R, Robinson KL, Burchard J, Bartz SR, Cleary M, Galloway DA, Grandori C. 2011. Gene expression signature of c-MYC-immortalized human fibroblasts reveals loss of growth inhibitory response to TGF- $\beta$. Cell Cycle 10: 2540-2548.

Welcker M, Orian A, Jin J, Grim JA, Harper JW, Eisenman RN, Clurman BE. 2004. The Fbw7 tumor suppressor regulates glycogen synthase kinase 3 phosphorylationdependent c-Myc protein degradation. Proc Natl Acad Sci 101: 9085-9090.

* Wiese K, Walz S, von Eyss B, Wolf E, Athineos D, Sansom O, Eilers M. 2013. The role of MIZ-1 in MYC-dependent tumorigenesis. Cold Spring Harb Perspect Med 4: a014290.

Zeller KI, Jegga AG, Aronow BJ, O’Donnell KA, Dang CV. 2003. An integrated database of genes responsive to the Myc oncogenic transcription factor: Identification of direct genomic targets. Genome Biol 4: R69.

Zhang H, Fang Y, Huang C, Yang X, Ye Q. 2005. Human pescadillo induces large-scale chromatin unfolding. Sci China C Life Sci 48: 270-276.

Zhang Z, Sun H, Dai H, Walsh RM, Imakura M, Schelter J, Burchard J, Dai X, Chang AN, Diaz RL, et al. 2009. MicroRNA miR-210 modulates cellular response to hypoxia through the MYC antagonist MNT. Cell Cycle 8: 27562768.

Zuber J, Shi J, Wang E, Rappaport AR, Herrmann H, Sison EA, Magoon D, Qi J, Blatt K, Wunderlich M, et al. 2011. RNAi screen identifies Brd4 as a therapeutic target in acute myeloid leukaemia. Nature 478: 524-528. 


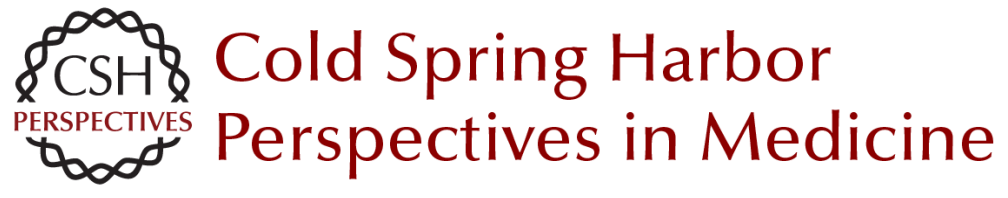

\section{Synthetic Lethal Screens as a Means to Understand and Treat MYC-Driven Cancers}

Silvia Cermelli, In Sock Jang, Brady Bernard and Carla Grandori

Cold Spring Harb Perspect Med 2014; doi: 10.1101/cshperspect.a014209

Subject Collection MYC and the Pathway to Cancer

MYC Cofactors: Molecular Switches Controlling

Diverse Biological Outcomes Stephen R. Hann

MYC Association with Cancer Risk and a New Model of MYC-Mediated Repression Michael D. Cole

MYC and the Art of MicroRNA Maintenance James N. Psathas and Andrei Thomas-Tikhonenko

MYC Activation Is a Hallmark of Cancer Initiation and Maintenance Meital Gabay, Yulin Li and Dean W. Felsher

MYC and Mitochondrial Biogenesis Fionnuala Morrish and David Hockenbery

Synthetic Lethal Screens as a Means to Understand and Treat MYC-Driven Cancers Silvia Cermelli, In Sock Jang, Brady Bernard, et al.

An Overview of MYC and Its Interactome Maralice Conacci-Sorrell, Lisa McFerrin and Robert N. Eisenman

Socializing with MYC: Cell Competition in Development and as a Model for Premalignant Cancer

Laura A. Johnston
MYC and the Control of Apoptosis Steven B. McMahon

Therapeutic Strategies to Inhibit MYC Michael R. McKeown and James E. Bradner

MYC and the Control of DNA Replication David Dominguez-Sola and Jean Gautier

MYC Regulation of Cell Growth through Control of Transcription by RNA Polymerases I and III Kirsteen J. Campbell and Robert J. White

MYC Degradation Amy S. Farrell and Rosalie C. Sears

MYC and Transcription Elongation Peter B. Rahl and Richard A. Young

c-MYC-Induced Genomic Instability Alexandra Kuzyk and Sabine Mai

Oncogenic Mechanisms in Burkitt Lymphoma Roland Schmitz, Michele Ceribelli, Stefania Pittaluga, et al.

For additional articles in this collection, see http://perspectivesinmedicine.cshlp.org/cgi/collection/ 